Atıf için: M. ZEYBEK, S. YILDIZ, "Gönen Çayı (Balıkesir-Çanakkale) Trichoptera Faunasının Belirlenmesine Yönelik Bir Araştırma", Süleyman Demirel Üniversitesi Fen Edebiyat Fakültesi Fen Dergisi, 14(2), 335-344, 2019.

\title{
Gönen Çayı (Balıkesir-Çanakkale) Trichoptera Faunasının Belirlenmesine Yönelik Bir Araştırma
}

\author{
Melek ZEYBEK ${ }^{* 1}$, Seray YILDIZ ${ }^{2}$ \\ ${ }^{1}$ Süleyman Demirel Üniversitesi, Fen Edebiyat Fakültesi, Biyoloji Bölümü, 32260, Isparta, Türkiye \\ ${ }^{2}$ Ege Üniversitesi, Su Ürünleri Fakültesi, Temel Bilimler Bölümü, 35040, İzmir, Türkiye \\ *yazışılan yazar e-posta: melekzeybek@sdu.edu.tr
}

(Alınış / Received: 12.09.2019, Kabul / Accepted: 15.10.2019, Yaylmlanma / Published: 30.11.2019)

Özet: Çalışma alanı olarak seçilen Gönen Çayı, Marmara Havzası'nın Çanakkale-Balıkesir kesimindeki en önemli akarsulardan biridir. Yaklaşık uzunluğu 134 km'dir. Özellikle son yıllarda yoğun tarım, hayvancılık ve madencilik faaliyetlerinden olumsuz olarak etkilenmekte ve çeşitli kirletici etkilere maruz kalmaktadır. Bu çalışmada Gönen Çayı'nın Trichoptera faunasının belirlenmesi amaçlanmış, Eylül 2010 ve Temmuz 2012 tarihleri arasında arazi çalışmaları gerçekleştirilmiş ve seçilen 12 istasyondan mevsimsel periyotlarla (8 arazi çalışması) örnekler alınmıştır. Çalışma sonunda, Gönen Çayı'nın Trichoptera (Insecta) faunasının 9 familya ve 16 cinse ait 28 tür tarafından temsil edildiği belirlenmiştir. Belirlenen familyalardan Hydropsychidae en fazla tür çeşitliliğine sahipken (9 tür), bunu sirasılyla Polycentropodidae ve Psychomyiidae (5'er tür), Glossossomatidae (3 tür) ve Limnephilidae (2 tür) izlemiştir. Goeridae, Lepidostomatidae, Rhyacophilidae ve Odontoceridae familyaları ise birer taksonla temsil edilmiştir.

Anahtar kelimeler: Trichoptera, Fauna, Gönen Çayı, Balıkesir, Çanakkale

\section{An Investigation on the Trichoptera Fauna of Gönen Stream (Balıkesir- Çanakkale)}

\begin{abstract}
Gönen Stream, selected as the study area, is one of the most important rivers in the Çanakkale-Balıkesir part of the Marmara Basin. Its approximate length is $134 \mathrm{~km}$. Especially in recent years, it is adversely affected by intensive agriculture, farming and mining activities and is exposed to various pollutant effects. This study was aimed to determine Trichoptera fauna of Gönen Stream. Field studies were carried out between September 2010 and July 2012 and samples were taken from 12 selected stations in seasonal periods ( 8 field studies). At the end of the study, it was determined that Trichoptera (Insecta) fauna of Gönen Stream was represented by 28 species belonging to 16 genera and 9 families. Among the identified families, Hydropsychidae has the highest species diversity (9 species), followed by Polycentropodidae and Psychomyiidae (5 species each), Glossossomatidae (3 species) and Limnephilidae (2 species) respectively. Goeridae, Lepidostomatidae, Rhyacophilidae and Odontoceridae families were represented by a taxon respectively.
\end{abstract}

Key words: Trichoptera, Fauna, Gönen Stream, Balıkesir, Çanakkale 


\section{Giriş}

Kullanılabilir su kaynaklarının çeşitli etkenlerle hızla kirletilerek bozulması sonucu, birçok dünya ülkesinde su ihtiyacı artarken temiz su kaynakları azalmaktadır. Bu durum nedeniyle hem ülkemizde hem de diğer dünya devletlerinde doğal kaynakların doğru kullanılmasını ve korunmasını sağlamak için çeşitli politikalar geliştirilmektedir. Avrupa Birliği üye ülkeler tarafından uygulanan Su Çerçeve Direktifi bu yönergelerden biridir. Su Çerçeve Direktifi'nin akarsulara uygulanmasında, bentik makroomurgasızlar önemli indikatörler olarak ele alınmıştır. Trichoptera takımı üyeleri, akarsularda yaşayan ve su kalitesini belirleme çalışmalarında biyolojik izleme aracı olarak kullanılan önemli bentik makroomurgasızlardandır [1]. Sedimentasyon, endüstriyel kirlilik, maden ve tarım, kanalizasyon atıkları, asit yağmurları su yüzeyinde biriktiğinde bu canlılar zarar görürler [2].

Dünyada yaklaşık 49 familya, 616 cins ve 14548 türü bilinen Trichoptera takımı [3, 4], Türkiye'de 20 familya, 80 cinse ait 481 tür ile temsil edilmektedir [5]. Türkiye Trichoptera faunasının ortaya çıkarılmasına yönelik yapılmış çeşitli faunistik çalışmalar olduğu gibi, bu takıma ait üyelerin biyolojik gösterge olarak kullanıldığı ekolojik tabanlı çalışmalar da mevcuttur [5, 6-17].

Çalışma alanı olarak seçilen Gönen Çayı, tarım ve hayvancılık faaliyetlerinin yoğun olarak yapıldığ kaynaklanan atıkların dere ve akarsulara bırakıldığ 1 bir bölgede yer almaktadır. Ayrıca üst havzada bulunan sanayi tesisleri ve yerleşim yerlerinin atık su arıtma tesislerinin yetersiz olması ve/veya tam kapasite ile kullanılmamasından kaynaklı atık sular, köylerin fosseptik ve katı atık sistemlerinin yetersiz olması ve beşerî faaliyetler sebebiyle alanın kirlilik yükü artmakta ve bunun sonucu olarak ta tür çeşitliliği azalmaktadir.

Bu araştırmada; Marmara Bölgesi'nde yer alan Gönen Çayı'nın (Balıkesir-Çanakkale) Trichoptera takımına ait tür çeşitliliğinin ortaya konması, türlerin bölgesel ve mevsimsel dağılışlarının tespit edilmesi amaçlanmıştır.

\section{Materyal ve Metot}

\section{1 Çalışma alanı}

Gönen Çayı, Marmara Havzası'nın Çanakkale-Balıkesir kesimindeki en önemli akarsulardan biridir. Kazdağı eteklerinden doğan çay, kıvrımlar yaparak batıdan Kocadere'yi, doğudan Çakıroba Çayı'nı alarak Marmara Denizi' ne dökülür. Gönen Çayı deltasını oluşturan bu akarsu bir ana kol ve üç yan koldan meydana gelir. Drenaj alanı $2174 \mathrm{~km}^{2}$, ana kol uzunluğu $134 \mathrm{~km}$, doğduğu yerde rakım 850 m’ dir [18].

Akarsu üzerinde 12 istasyon belirlenmiş, Eylül 2010 ve Temmuz 2012 tarihleri arasında mevsimsel periyotlarla (Eylül 2010, Aralık 2010, Mart 2011, Haziran 2011, Eylül 2011, Aralık 2011, Nisan 2012 ve Temmuz 2012) Trichoptera örnekleri alınarak incelenmiştir (Şekil 1). Belirlenen istasyonların koordinat ve rakım bilgileri Tablo 1 de verilmiştir. 


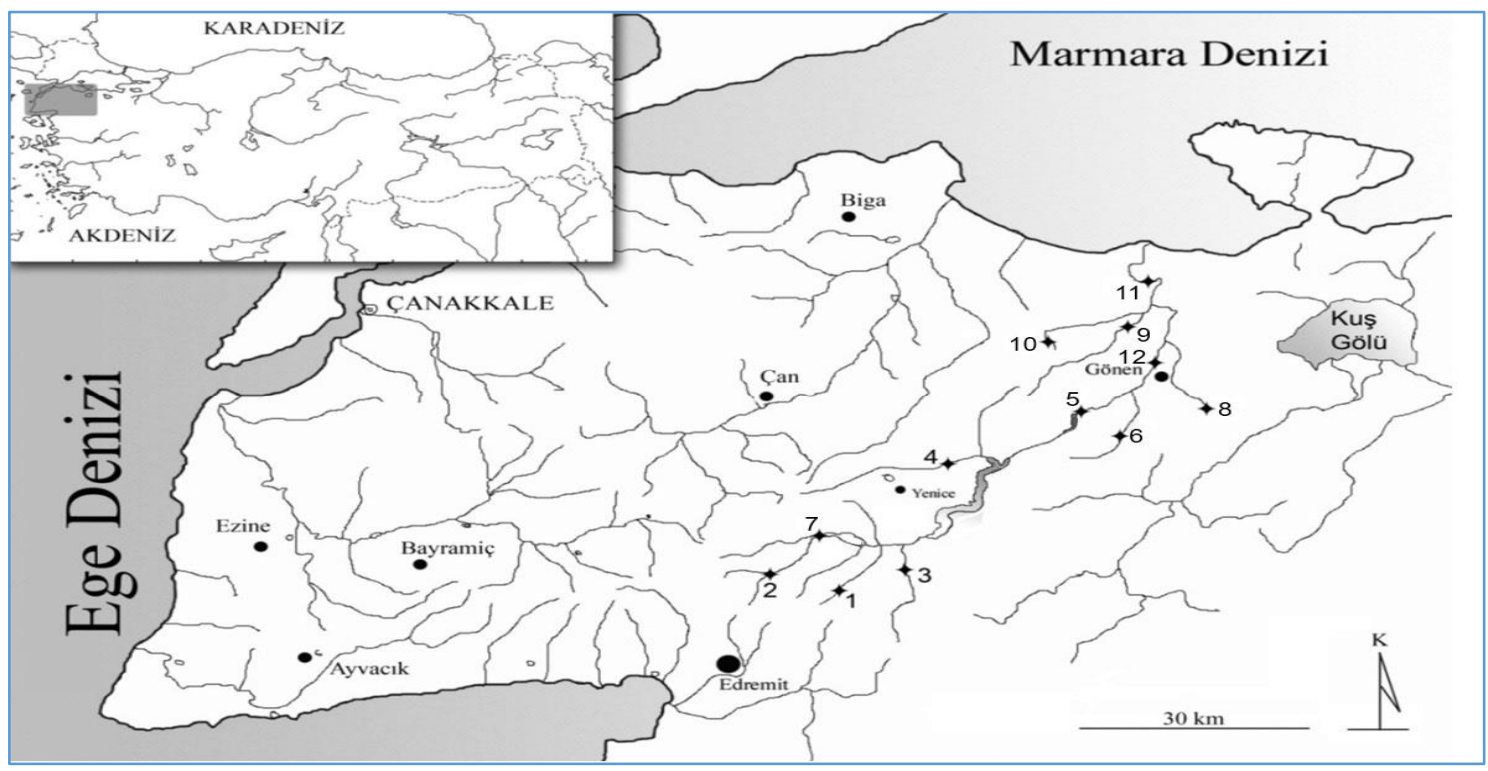

Şekil 1. Çalışma alanı ve istasyonlar

Tablo 1. İstasyonların rakım ve koordinat bilgileri

\begin{tabular}{ccccc}
\hline & İstasyonlar & Rakım $(\mathbf{m})$ & \multicolumn{2}{c}{ Koordinatları } \\
\hline 1 & Han Dere & 330 & $39^{\circ} 45^{\prime} 16^{\prime \prime} \mathrm{K}$ & $27^{\circ} 12^{\prime} 39^{\prime \prime} \mathrm{D}$ \\
2 & Kovanlık Çayı & 254 & $39^{\circ} 49^{\prime} 40^{\prime \prime} \mathrm{K}$ & $27^{\circ} 08^{\prime} 51^{\prime \prime} \mathrm{D}$ \\
3 & Kocaçay & 180 & $39^{\circ} 50^{\prime} 07^{\prime \prime} \mathrm{K}$ & $27^{\circ} 19^{\prime} 56^{\prime \prime} \mathrm{D}$ \\
4 & Çakırköy Deresi & 186 & $29^{\circ} 57^{\prime} 51^{\prime \prime} \mathrm{K}$ & $27^{\circ} 22^{\prime} 42^{\prime \prime} \mathrm{D}$ \\
5 & Gönen Regülatör Savağ & 63 & $40^{\circ} 02^{\prime} 44^{\prime \prime} \mathrm{K}$ & $27^{\circ} 33^{\prime} 10^{\prime \prime} \mathrm{D}$ \\
6 & Han Dere (Cambaz Köyü) & 64 & $40^{\circ} 03^{\prime} 16^{\prime \prime} \mathrm{K}$ & $27^{\circ} 37^{\prime} 46^{\prime \prime} \mathrm{D}$ \\
7 & Biçk1 Dere & 293 & $39^{\circ} 51^{\prime} 24^{\prime \prime} \mathrm{K}$ & $27^{\circ} 14^{\prime} 04^{\prime \prime} \mathrm{D}$ \\
8 & Tütüncüler Deresi & 70 & $40^{\circ} 04^{\prime} 06^{\prime \prime} \mathrm{K}$ & $27^{\circ} 42^{\prime} 51^{\prime \prime} \mathrm{D}$ \\
9 & Keçidere, Kocadere & 32 & $40^{\circ} 11^{\prime} 28^{\prime \prime} \mathrm{K}$ & $27^{\circ} 37^{\prime} 01^{\prime \prime} \mathrm{D}$ \\
10 & Çakıroba Çayı & 61 & $40^{\circ} 11^{\prime} 08^{\prime \prime} \mathrm{K}$ & $27^{\circ} 31^{\prime} 15^{\prime \prime} \mathrm{D}$ \\
11 & Gönen Çay1 Anakol (Gebeçınar Köyü) & 23 & $40^{\circ} 15^{\prime} 20^{\prime \prime} \mathrm{K}$ & $27^{\circ} 37^{\prime} 54^{\prime \prime} \mathrm{D}$ \\
12 & Gönen Çayı Anakol (Gönen ilçesi köprü altı) & 33 & $40^{\circ} 06^{\prime} 39^{\prime \prime} \mathrm{K}$ & $27^{\circ} 38^{\prime} 45^{\prime \prime} \mathrm{D}$ \\
\hline
\end{tabular}

\subsection{Trichoptera örneklerinin toplanması}

$180 \mu \mathrm{m}$ göz açıklığındaki el bentik kepçeleri ve $500 \mu \mathrm{m}$ göz açıklığındaki kick-net ile tekmeleme ve süpürme yöntemleri ile 10 dakikalık standart metotla toplanan organizmalar, arazide \% 4'lük formolde tespit edilmiştir. Kick-net ile yapılan örneklemelerde, her istasyonda birkaç ayrı kesimden örnek alınacak şekilde bentik örneklemeler yapılmıştır. Laboratuvarda bol su ile yıkanan canlılar arasından ayıklanan Trichoptera bireyleri \%70'lik alkole alınıp saklanmıştır. Elde edilen örnekler stereomikroskop ve lup altında incelenerek, kalitatif ve kantitatif olarak değerlendirilmiştir. Örneklerin teşhisinde, Edington ve Hildrew [19], Wallace vd. [20] kaynaklarından yararlanılmıştır.

\section{Bulgular}

Toplanan örneklerin incelenmesi sonucunda, Gönen Çayı'nın (Balıkesir-Çanakkale) Trichoptera (Insecta) faunasinın 9 familya ve 16 cinse ait 28 tür tarafindan temsil edildiği tespit edilmiştir.

Belirlenen familyalardan Hydropsychidae en fazla tür çeşitliliğine sahipken (9 tür), bunu sirasıyla Polycentropodidae ve Psychomyiidae (5'er tür), Glossossomatidae (3 tür) ve Limnephilidae (2 tür) izlemiştir. Goeridae, Lepidostomatidae, Rhyacophilidae ve 
Odontoceridae familyaları ise birer taksonla temsil edilmiştir. Saptanan Trichoptera taksonlarının sistematik konumları aşağıda verilmiştir.

\section{PHYLUM: ARTHROPODA \\ SUBPHYLUM: HEXAPODA \\ CLASSIS: INSECTA \\ SUBCLASSIS: PTERYGOTA \\ ORDO: TRICHOPTERA}

\section{Familya: Polycentropodidae}

Polycentropus irroratus (Curtis, 1835)

Cyrnus trimaculatus (Curtis, 1834)

Cyrnus flavidus (McLachlan, 1864)

Cyrnus insolutus (McLachlan, 1878)

Plectrocnemia geniculata (McLachlan, 1871)

\section{Familya: Hydropsychidae}

Hydropsyche pellucidula (Curtis, 1834)

Hydropsyche instabilis (Curtis, 1834)

Hydropsyche contubernalis (McLachlan, 1865)

Hydropsyche exocellata (Dufour, 1841)

Hydropsyche saxonica (McLachlan, 1884)

Hydropsyche fulvipes (Curtis, 1834)

Hydropsyche angustipennis (Curtis, 1834)

Diplectrona felix (McLachlan, 1878)

Cheumatopsyche lepida (Pictet, 1834)

Familya: Glossossomatidae

Glossosoma conformis (Neboiss, 1963)

Glossosoma intermedium (Klapálek, 1892)

Agapetus fuscipes (Curtis, 1834)

\section{Familya: Psychomyiidae}

Tinodes rosrocki (McLachlan, 1878)

Tinodes maclachlani (Kimmins, 1966)

Tinodes unicolor (Pictet, 1834)

Lype phaeopa (Stephens, 1836)

Lype reducta (Hagen, 1868)

\section{Familya: Limnephilidae}

Limnephilus griseus (Linnaeus, 1758)

Mesophylax impunctatus (McLachlan, 1884)

\section{Familya: Goeridae}

Goera pilosa (Fabricius, 1775)

Familya: Rhyacophilidae

Rhyacophila obliterata (McLachlan, 1863)

Familya: Lepidostomatidae

Lasiocephala basalis (Kolenati, 1848)

Familya: Odontoceridae

Odontocerum albicorne (Scopoli, 1763)

Trichoptera taksonlarının istasyonlara göre dağılımları incelendiğinde; Hydropsyche instabilis 7 istasyonda tespit edilmiş olup en fazla rastlanan tür olmuştur. Bu türü 5 istasyonda tespit edilen Hydropsyche contubernalis ve Lype phaeopa türleri takip etmiştir. 5., 7., 11., ve 12. istasyonlarda Trichoptera türlerine rastlanmamıştır (Tablo 2). 


\begin{tabular}{|c|c|c|c|c|c|c|c|c|c|c|c|c|}
\hline & \multicolumn{12}{|c|}{ İSTASYONLAR } \\
\hline İstasyon No & 1 & 2 & 3 & 4 & 5 & 6 & 7 & 8 & 9 & 10 & 11 & 12 \\
\hline \multicolumn{13}{|l|}{ Polycentropodidae } \\
\hline Cyrnus flavidus & & + & & & & & & & & & & \\
\hline Cyrnus insolutus & & + & & & & & & & & & & \\
\hline Cyrnus trimaculatus & & + & & & & & & & & & & \\
\hline Plectrocnemia geniculata & & + & & & & & & & & & & \\
\hline $\begin{array}{l}\text { Polycentropus irroratus } \\
\text { Hydropsychidae }\end{array}$ & + & + & & & & & & & & & & \\
\hline Cheumatopsyche lepida & & & & & & + & & & & & & \\
\hline Diplectrona felix & + & + & + & & & + & & & & & & \\
\hline Hydropsyche angustipennis & & + & + & & & & & & & & & \\
\hline H.contubernalis & & + & + & + & & + & & & & + & & \\
\hline H.exocellata & & & + & + & & & & & + & + & & \\
\hline H.fulvipes & & & + & & & & & & & & & \\
\hline H.instabilis & & + & + & + & & + & & + & + & + & & \\
\hline H.pellucidula & + & + & + & + & & & & & & & & \\
\hline H.esaxonica & & & + & + & & & & & & & & \\
\hline \multicolumn{13}{|l|}{ Glossossomatidae } \\
\hline Agapetus fuscipes & + & + & & & & & & & & & & \\
\hline Glossosoma conforme & + & & & & & & & & & & & \\
\hline G.intermedium & + & & & & & & & & & & & \\
\hline \multicolumn{13}{|l|}{ Psychomyiidae } \\
\hline Lype phaеopa & & + & + & + & & & & & + & + & & \\
\hline L.reducta & & & & & & & & & & + & & \\
\hline Tinodes maclachlani & + & & & & & & & & & & & \\
\hline T.rostocki & + & & & & & & & & & & & \\
\hline T.unicolor & & + & & + & & & & & & + & & \\
\hline \multicolumn{13}{|l|}{ Limnephilidae } \\
\hline Limnephilus griseus & + & & & & & & & & & & & \\
\hline $\begin{array}{l}\text { Mesophylax impunctatus } \\
\text { Goeridae }\end{array}$ & + & & & & & & & & & & & \\
\hline Goera pilosa & + & & & & & & & & & & & \\
\hline Rhyacophilidae & & & & & & & & & & & & \\
\hline Rhyacophila obliterata & & & + & & & & & & & & & \\
\hline Lasiocephala basalis & + & & & & & & & & & & & \\
\hline Odontoceridae & & & & & & & & & & & & \\
\hline Odontocerum albicorne & + & & & & & & & & & & & \\
\hline Toplam Takson Sayısı & 13 & 12 & 10 & 7 & 0 & 4 & 0 & 1 & 3 & 6 & 0 & 0 \\
\hline
\end{tabular}

Trichoptera taksonlarının mevsimsel dağılımları incelendiğinde; en fazla takson Sonbahar (Eylül'10) örneklemesinde (22 takson) gözlenmiş olup, sirasıyla Yaz (Haziran'11) (11 takson), Yaz (Temmuz'12) (10 takson) izlemektedir. En düşük tür çeşitliliği ise Kış (Aralık’10) mevsiminde gözlenmiştir (1 takson) (Tablo 3). 
Tablo 3. Gönen Çayı Trichoptera taksonlarının mevsimlere göre dağılımı ve birey sayısı

\begin{tabular}{|c|c|c|c|c|c|c|c|c|c|c|c|c|c|c|c|c|}
\hline & \multicolumn{5}{|c|}{ 司 } & $\frac{0}{\frac{1}{\bar{z}}}$ & $\underset{\Sigma}{E}$ & \multicolumn{2}{|c|}{ ב } & \multicolumn{2}{|c|}{$\equiv$} & 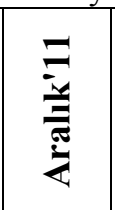 & \multicolumn{2}{|c|}{ 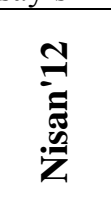 } & \multicolumn{2}{|c|}{ 坣 } \\
\hline & \multicolumn{16}{|c|}{$\begin{array}{c}\text { Türlerin belirlendikleri istasyonlara göre dağılımları } \\
\text { ve birey sayıları }\end{array}$} \\
\hline & \multicolumn{16}{|c|}{ İstasyonlar } \\
\hline Türler & 1 & 2 & 4 & 1 & 10 & 9 & 6 & 2 & 3 & 8 & 9 & 36 & 1 & 2 & 2 & 3 \\
\hline Crynus flavidus & & 1 & & & & & & & & & & & & & & \\
\hline C. insolutus & & 1 & & & & & & & & & & & & & & \\
\hline C. trimaculatus & & 1 & & & & & & & & & & & & & & \\
\hline $\begin{array}{l}\text { Plectrocnemia } \\
\text { geniculata }\end{array}$ & & 1 & & & & & & & & & & & & & & \\
\hline Polycentropus irroratus & 1 & & & & & & & 1 & & & & & & & 1 & \\
\hline Cheumatopsyche lepida & & & & & & & 1 & & & & & & & & & \\
\hline Diplectrona felix & & 1 & & & & & 2 & 1 & 2 & & & 1 & 1 & & 1 & 3 \\
\hline $\begin{array}{l}\text { Hydropsyche } \\
\text { angustipennis }\end{array}$ & & & & & & & & 1 & 4 & & & & & & 1 & 1 \\
\hline H.contubernalis & & 1 & 3 & & 4 & & 1 & & 1 & & & & & & & 1 \\
\hline H. exocellata & & & 3 & 1 & 1 & & & & 3 & & 1 & & & & & 3 \\
\hline H. fulvipes & & & & & & & & & 1 & & & & & & & \\
\hline H. instabilis & & 1 & 5 & 1 & 3 & & & & 4 & 1 & 4 & 2 & & 1 & & 4 \\
\hline H. pellucidula & 1 & 1 & 6 & & & & & 2 & 9 & & & & & & 1 & \\
\hline H. saxonica & & & 1 & & & & & & 6 & & & & & & & 3 \\
\hline Agapetus fuscipes & & & & & & & & & & & & & 1 & 25 & & \\
\hline Glossoma conforme & 1 & & & & & & & & & & & & & & & \\
\hline G.intermedium & 1 & & & & & & & & & & & & & & & \\
\hline Lype phaeopa & & 4 & 2 & & 7 & 1 & & & 2 & & 1 & & & & & 2 \\
\hline L.reducta & & & & & 6 & & & & & & & & & & & \\
\hline Tinodes maclachlani & & 1 & & & & & & & & & & & & & & \\
\hline T. rostocki & 1 & & & & & & & & & & & & & & & \\
\hline T. unicolor & & 2 & 1 & & 3 & & & & & & & & & & & \\
\hline Limnephilus griseus & 1 & & & & & & & & & & & & & & & \\
\hline Mesophylax & 1 & & & & & & & & & & & & & & & \\
\hline $\begin{array}{l}\text { impunctatus } \\
\text { Goera pilosa }\end{array}$ & 1 & & & & & & & & & & & & & & & \\
\hline Rhyacophila obliterata & & & & & & & & & 1 & & & & & & & 1 \\
\hline Lasiocephala basalis & & & & & & & & & & & & & 1 & & & \\
\hline Odontocerum albicorne & 1 & & & & & & & & & & & & & & & \\
\hline
\end{tabular}

\section{Sonuç ve Yorum}

Trichoptera takımının dünyada yaklaşık 49 familyası, 616 cinsi, 14.548 türü bulunmaktadır. Bunlardan 26 familya ve 1.888 tür Batı Palaearktik’te bulunmaktadır [3, 4]. Türkiye Trichopterafaunası ise, 21 familyanın 80 cinsinin 481 taksonu (449 tür 32 alt tür) ile temsil edilmektedir [5]. Bu takıma ait üyeler; lotik sistemlerde yaşayan önemli bentik makroomurgasızlardandır. Özellikle hızlı akıntılı sularda olmaları ve genelde bu takıma mensup bireylerin temizlik indikatörü olması sebebi ile önem kazanırlar. $\mathrm{Bu}$ çalışmada Gönen Çayı üzerinde belirlenen 12 istasyondan, iki yıl boyunca mevsimsel periyotlarla yapılan örneklemeler sonucunda; Trichoptera takımına ait 28 takson belirlenmiştir. İncelenen örneklerde en fazla birey, Hydropsychidae [Hydropsyche pellucidula (Curtis, 1834), H. instabilis (Curtis, 1834), H.contubernalis 
(McLachlan,1865), H.exocellata (Dufour,1841), H.saxonica (McLachlan, 1884), H. fulvipes (Curtis, 1834), H.angustipennis (Curtis, 1834), Diplectrona felix (McLachlan, 1878), Cheumatopsyche lepida (Pictet, 1834)] familyasına aittir. Çoğunlukla kozmopolit bir familya olarak bilinen Hydropsychidae üyelerinin çözünmüş oksijen, 1sı, akım hızı gibi faktörlere göre dağılımlarının farklı olabileceği belirtilmektedir [21, 22].

Belirlenen taksonlardan Lasiocephala basalis, Diplectrona felix, Rhyacophila obliterata, Hydropsyche instabilis ve Tinodes unicolor organik kirliliğe karşı çok hassas; Hydropsyche pellucidula, H. saxonica, Mesophylax impunctatus ve Cheumatopsyche lepida hassas; Cyrnus trimaculatus, C. flavidus, C. insolutus, Hydropsyche contubernalis, H. fulvipes ve H. angustipennis toleransl1; Hydropsyche exocellata yüksek toleranslı organizmalar grubunda yer almaktadır [23].

Çalışma süresinde en fazla bireyle temsil edilen türler sırasıyla Agapetus fuscipes, Hydropsyche pelludicula, $H$. instabilis olmuştur.

H. pellucidula, bu türün habitatı, dere ve ırmak, alabalıkların yaşadığı bölgelerin üst kısmı, alabalıkların yaşadığı bölgelerin alt kısmı, Tymallus balığının yaşadığı bölge, Barbus balığının yaşadığı bölge olarak bildirilmiştir [15, 24, 25]. DIN38410 [26]'a göre bu takson beta-mezosaprob bölgenin organizmaları arasında yer almaktadır.

H. instabilis, bu çalışmada en fazla dağılım gösteren takson olarak belirlenmiştir. Yüksek ve orta akıntılı bölgeleri tercih ettiği ifade edilen $H$. instabilis'in $150 \mathrm{~m}$ 'den yüksek alanlarda görüldüğü belirtilmektedir [2]. Ancak bu çalışmada dağılım gösterdiği yükselti sınırları açısından literatürden sapma göstermiş ve dağılım yüksekliği $32 \mathrm{~m}$ düzeyinden başlamıştır. DIN38410 [26]'a göre bu takson oligo-betamesosaprob bölgenin organizmalarındandır. Genel olarak akışın hızlı olduğu nehir ve derelerde bol olarak bulunan bu tür, Türkiye'de geniş bir yayılım göstermektedir [5, 27, 28].

H. angustipennis'in her türlü akıntılı ya da durgun akarsu ve nehirlerde taşların altında bulunabildiği rapor edilmiştir [19] Bu çalışmada Kovanlık Çayı (rakım 254 m) ve Kocaçay'da (rakım $180 \mathrm{~m}$ ) tespit edilmiştir. Kozmopolit bir tür olan H. angustipennis'in oldukça geniş bir yayılım alanı vardır [24].

H. contubernalis, beş farkl1 istasyonda belirlenmiş ve bulunduğu rakım değerleri 61-254 $\mathrm{m}$ arasında değişim göstermiştir. Bu türün 1000 m'ye kadar rakımda ve akıntı hızının fazla olduğu alanlarda dağılım gösterdiği bildirilmiştir [2]. Elde edilen sonuçlar literatür bilgisi ile benzerlik göstermektedir.

H. fulvipes taksonuna Kocaçay'da (3.istasyon) rastlanılmıştır. Graf vd. [2]'ne göre ökrenal, hipokrenal ve epiritral bölgelerde dağılım gösteren bu takson $150 \mathrm{~m}$ den yüksek alanlarda dağılım göstermektedir. Tespit edildiği istasyonun rakımı 180 m'dir. Yükselti açısından literatür ile uyum içerisindedir. Darılmaz ve Salur [5] bu türün sadece Ankara Çayı'nda belirlendiğini ifade etmektedirler. Ancak bu takson Antalya havzasında da yayılım göstermektedir [29-31]. Zeybek ve Şahin [17] bu taksonun Munzur Çayı'nda yayılış gösterdiğini belirtmişlerdir.

H. exocellata, dip yapısı kaya ve kum, suyu berrak, hızlı akan akarsu kenarında yaşar [2]. Bu çalışmada dört istasyonda gözlenmiştir. 
Cheumatopsyche lepida türünün 150 m'den yüksek alanlarda görüldüğü ve yüksek akıntılı bölgeleri tercih ettiği belirtilmektedir [2]. Bu çalışmada ise sadece Han Dere (6.istasyon) üzerinde belirlenmiştir ve bu istasyonun rakımı 64 m'dir. Rakımın 150 m'nin üzerinde olduğu istasyonlarda bu türe rastlanılmamıştır. Bu nedenle, bu tür ile ilgili olarak elde edilen sonuçların literatür bilgisi ile uyumlu olmadığı söylenebilir. Ülkemiz şartlarında türün ekolojik balansını genişlettiğini düşünmekteyiz.

Beş farklı istasyonda belirlenen Diplectrona felix karasal bitkinin bol bulunduğu ormanlık alanda, genellikle taş ve kayalık biyotoplar ile şelalelerin döküldügüu, kalkerli ve çamurlu zeminlerde yaşar [2].

Agapetus cinsine ait türlerin hızlı akıntılı, kaynağa yakın bölgeleri tercih ettiği bilinmektedir ve bu alanlar kirlilikten uzak bölgeler olarak belirtilmektedir. Bu karakterdeki bölgelerin referans türü olarak söylenebilir [32]. Bu çalışmada kaynak bölgesine yakın bir alanda yer alan 1. ve 2. istasyonda Agapetus fuscipes türü tespit edilmiştir. Elde edilen veriler, bu bilgileri destekler niteliktedir.

Johnson ve Goedkoop [33] çalışmalarında Polycentropodidae familyasını hassas bir familya olarak belirtmiştir. Yapılan bu çalışmada da bu familyaya ait 5 farklı tür (Cyrnus flavidus, $C$. insolutus, $C$. trimaculatus, Plectrocnemia geniculata, Polycentropus irroratus) kaynağa yakın bir bölgede yer alan 1. ve 2. istasyonlarda gözlenmiştir.

Kovanlık Çayı üzerinde ve yalnızca sonbahar mevsiminde belirlenen Cyrnus trimaculatus türünün habitatının, dere, denize dökülen $1 \mathrm{rmak}$ ağzı ve acı sular, alabalıkların yaşadığı bölgelerin alt kısmı, Tymallus balığının yaşadığ balığının yaşadığı bölge, küçük göl, göl ağzı olduğu bildirilmiştir [24, 25].

Yalnızca 1. istasyonda belirlenen Tinodes rostocki'nin akıntı hızı yüksek suların epiritral ve metaritral bölgelerinde dağılım gösterdiği belirtilmektedir [2].

Rhyacophila obliterata sadece 5. istasyonda (Kocaçay) tespit edilmiştir. Belirlendiği rak1m 180 m'dir. DIN38410 [23]'a göre betamesosaprob bölgenin organizmalarındandır.

Biyolojik yönden su kalitesini belirlemeye yönelik çalışmalarda kullanılan saprobi indekse göre Trichoptera faunasının kalite sınıf aralığı oligosaprob ile betaalfamesosaprob arasında değişim göstermektedir. Bu da kalite sınıfı olarak I. kalite sınıfı ile II-III. kalite sınıfı arasında değişim göstermektedir. Saprobi değeri olarak en yüksek değere Cyrnus trimaculatus (2,5) sahipken, çok az Trichoptera taksonu 2,3 saprobi değeri üzerine çıkmaktadır. Hydropsyche cinsinden ise sadece Hydropsyche contubernalis $(2,4)$ beta-alfamesosaprob yani II-III. kalite sinifina dahil olmakta, Trichoptera takımından hiçbir organizma III., III-IV. ve IV. kalite sınıflarında dağglım göstermemektedir [26]. Bu çalışmada belirlenen organizmaların büyük çoğunluğu temiz veya az kirlenmiş akarsu bölümlerinde dağılış gösteren organizmalar olmakla birlikte organik kirliliğe karşı toleranslı türlere de rastlanılmıştır. Bu durum, çalışma alanının ve burada bulunan organizmaların kirletici etki altında bulunduğunun göstergesi olabilir. Gönen Çayı Havzasının neredeyse tamamında yoğun tarımsal faaliyetler söz konusudur. Ayrıca, bölgede yoğun olarak hayvancılık yapılmakta ve bu faaliyetler sonucu oluşan artıkların çoğunlukla en yakın su ortamına, derelere akıtıldığı bilinmektedir. Yine havzadaki küçük köylerin evsel atıkları da kontrolsüz şekilde derelere ve çevresine 
bırakılmaktadır. Tüm bunların yanı sıra, son yıllarda bölgede madencilik faaliyetleri de başlamıştır. Tüm bu olumsuz şartlar özellikle akarsu havzasının kirlilik yükünün artışına neden olmakta ve havzanın biyoçeşitliliğini etkilemektedir [34].

Bu çalışmada Gönen Çayı'nın Trichoptera faunasının tespit edilmesi amaçlanmıştır. Bu ve buna benzer çalışmalar Türkiye Trichoptera faunasına katkı yapacak ve diğer sistematik ve ekolojik çalışmalara 1şık tutacaktır.

\section{Teșekkür}

Bu çalışma, Ege Üniversitesi Bilimsel Araştırma Projeleri Şube Müdürlügü tarafından, 2010/SÜF/02 no'lu proje ile desteklenmiştir.

\section{Kaynakça}

[1] S. U. Pauls, W. Graf, P. Haase, H. T. Lumbsch, and J. Waringer, "Grazers, shredders and filtering carnivores - the evolution of feeding ecology in Drusinae (Trichoptera: Limnephilidae): insights from a molecular phylogeny," Mol. Phylogenet. Evol., 46 (2), 776-791, 2008.

[2] W. Graf, J. Murphy, J. Dahl, J., C. Zamora-Muñoz, and M. J. López-Rodríguez, "Distribution and Ecological Preferences of European Freshwater Organisms" in Trichoptera, vol. 1, A. SchmidtKloiber, and D. Hering, Eds. Sofia-Moscow: Pensoft Publishers, 2008, pp. 388.

[3] J. C. Morse, “The Trichoptera world checklist," Zoosymposia, 5 (1), 372-380, 2011.

[4] J. C. Morse. (2016, 3 June) "Trichoptera World Checklist," Available: http. entweb. clemson. edu/data-http://and web. clemson. edu/data-. clemson. edu/database/trichopt/index.

[5] M. C. Darilmaz, A. Salur, "Annotated Catalogue of the Turkish Caddisflies (Insecta: Trichoptera)", Mun.Ent. Zool., 10 (Suppl.), 521-734, 2015.

[6] F. Çakın, "Some New Species and Records of Trichoptera in Turkey," Aquat Insec., 5 (4), 233-249, 1983.

[7] F. Sipahiler, H. Malicky, "DieKöcherfliegen der Türkei (Trichoptera)”, Entomofauna, 8, 77-165, 1987.

[8] H. Malicky, F. Sipahiler, "Köcherfliegen (Trichoptera) aus der Türkei, mit Bemerkungenzuweiterenmediterranen Köcherfliegen. Mitteilungen der Schweizerischen Entomologischen Gesellschaft," Bull. de la Soc. Entomol. Suisse, 66, 457-478, 1993.

[9] F. Sipahiler, "Studies on the Trichoptera Fauna of Southern Anatolia," Entomofauna, 17 (16), 293312, 1996.

[10] K. Kumanski, F. Sipahiler, "List of caddisflies (Insecta: Trichoptera) collected by Bulgarian scientists in Turkey. Hist. Nat. Bulg, 15, 127-137, 2002.

[11] S. Balık, R. Ustaoğlu, M. Özbek, A. Taşdemir, E. Topkara, "Yelköprü Mağarası (Dikili, İzmir) ve Yakın Çevresinin Sucul Faunası Hakkında Bir Ön Araştırma,” EgeJFas, 19 (1/2), 221-225, 2002.

[12] A. G. Yıldırım, “Aşağı Sakarya Nehir Sistemi Trichoptera Faunasının Tespiti,” Yüksek Lisans Tezi, Fen Bil. Enst., Eskişehir Osmangazi Üniv., Eskişehir,2002.

[13] Ç. Cengiz, "Kuzey Trakya Bölgesi Akarsu Sistemleri Trichoptera (Insecta) Limnofaunası Üzerine Araştırmalar," Yüksek Lisans Tezi, Fen Bil. Enst., Eskişehir Osmangazi Üniv., Eskişehir,2003.

[14] N. Yıldırım, "Fırnız Çayı (Kahramanmaraş)'nın Fiziko-kimyasal ve Bazı Biyolojik (Bentikmakroinvertebrat) Özellikleri,” Yüksek Lisans Tezi, Fen Bil. Enst., Kahramanmaraş Sütçü İmam Üniv., Kahramanmaraş, 2006.

[15] N. Arslan, S. İlhan, Y. Şahin, C. Filik, F. Yılmaz, T. Öntürk, "Diversity of Invertebrate Fauna in Littoral of Shallow Musaözü Dam Lake in Comparison with Environmental Parameters," JABS, 1 (3), 67-75, 2007.

[16] İ. Küçübasmac1, "Kastamaonu Trichoptera (Insecta) Faunas1,” Doktora Tezi, Fen Bil. Enst., Gazi Üniv., Ankara, 2008.

[17] M. Zeybek, S. Koşal Şahin, "The Distribution Of Trichoptera Assemblages In Relation To Environmental Variables In The Streams Of Tunceli (Turkey)," Fresen Environ Bull., 25 (11), 49724981, 2016.

[18] N. Kazancı, Ö. Emre, T. Erkal, Ö. İleri, M. Ergin, N. Görür, “ Kocasu ve Gönen Çayı deltalarının (Marmara Denizi güney kıyıları) güncel morfolojileri ve tortul fasiyesleri,” MTA Dergisi, 121:33-50, 1999.

[19] J. M. Edington, and A. G. Hildrew, Caseless Caddis Larvae of the British Isles. England: Freshwater Biological Association Scientific Publication, 1995, pp. 134.

[20] I. D. Wallace, B. Wallace, G. N. Philipson, Keys to the Case-bearing Caddis Larvae of Britain and Ireland. Freshwater Biological Association SP 61, 2003, pp. 1-259. 
[21] G. B. Wiggins, R. J. Mackay, "Some relationships between systematics and trophic ecology in Nearctic aquatic insects, with special reference to Trichoptera," Ecology, 59, 1-20, 1978.

[22] D. Williams, and B. Feltmate, Aquatic Insects, Wallingford, UK: CAB International, 1992, pp. 1358.

[23] V. H. Resh, and D. M. Rosenberg, Freshwater biomonitoring and benthic macroinvertebrates. New York, USA: Chapman \& Hall., 1993, pp. 1-504.

[24] J. Illies, Limnofauna europaea (2nd ed.). Stuttgart: Fischer, 1978, pp. 331-359.

[25] W. Graf and M. Konar, "Rote Liste der Köcherfliegen Kärntens (Insecta, Trichoptera). Rote Listen gefährdeter Tiere Kärntens", Naturschutz in Kärnten, 15, 201-212, 1999.

[26] DIN 38410, "Biologisch-ökologische Gewässeruntersuchung (Gruppe M) - Teil 1: Allgemeine Hinweise, Planung und Durchführung von Fließgewässeruntersuchungen (M1) - Bestimmung des Saprobienindex (M1)" Deutsche Einheitsverfahren zur Wasser-, Abwasser- und Schlammuntersuchung, Ausgabe 2004-10, 2004.

[27] F. Sipahiler, "Studies on the instabilis group of the genus Hydropsyche in Turkey (Trichoptera, Hydropsychidae)," Entomofauna, 25 (12), 181-220, 2004.

[28] M. Zeybek, H. Kalyoncu, Ö. O. Ertan, N. L. Çiçek, “Köprüçay Irmağı (Antalya) Bentik Omurgasız Faunası”, SDÜ Fen Bilimleri Enstitüsü Dergisi, 16 (2), 146-153, 2012.

[29] H. Kalyoncu, B. Yorulmaz, M. Barlas, M. Z. Yıldırım, M. Zeybek, “Aksu Çayı'nın Su Kalitesi ve Fizikokimyasal Parametrelerinin Makroomurgasız Çeşitliliği Üzerine Etkisi," Fırat Üni. Fen ve Mühendislik Bilimleri Dergisi, 20 (1): 23-33, 2008.

[30] H. Kalyoncu, M. Zeybek, "An Application Of Different Biotic And Diversity Indices For Assessing Water Quality: A Case Study In The Rivers Çukurca And Isparta (Turkey)," AJAR, 6 (1), 19-27, 2011.

[31] M. Zeybek, H. Kalyoncu, B. Karakaş ve S. Özgül, "The use of BMWP and ASPT indices for evaluation of water quality (according to macroinvertebrates) in Değirmendere Stream (Isparta, Turkey)," Tr J Zool, 38, 603-613, 2014.

[32] Ü. E. Keşir, “Ceyhan Nehri Trichoptera faunası,” 2016. Yüksek Lisans Tezi, Fen Bil. Enst., Nevşehir Hacı Bektaş Veli Üniversitesi, Nevşehir, 2016.

[33] R.K. Johnson, W. Goedkoop, Bedömningsgrunder för bottenfauna i sjöar och vattendrag: Anväändarmanual och bakgrundsdokument Swedish University of Agricultural Sciences, Report, 4, 2007, pp. 84.

[34] A. İlhan, H. M. Sarı, ve M. R. Ustaoğlu, "Gönen Çayı (Balıkesir) Balık Faunası,” J FisheriesSciences.com., 8(3), 194-198, 2014. 